\title{
EL GARANTISMO PENAL DE UN ILUSTRADO ITALIANO: MARIO PAGANO Y LA LECCIÓN DE BECCARIA
}

\author{
Dario Ippolito
}

RESUMEN. La teoría normativa del Derecho penal desarrollada por Francesco Mario Pagano debe situarse dentro de la tradición penal ilustrada que le precede, esto es, en la reflexión de Montesquieu y Beccaria. A partir de la influencia de estos autores, Pagano elabora las líneas generales de un proceso penal moderno cimentado en las garantías fundamentales del inculpado. La crítica que Pagano dirige contra el procedimiento inquisitorio, entonces vigente, no se articula sólo en el nivel del déficit de garantías del imputado - sobre el que se centraba la principal crítica de los defensores del modelo acusatorio-, además, el autor desafía a los apologetas de la inquisitio en su propio terreno: el de la interpelación represiva. Más allá de la denuncia que Pagano realiza en contra del método procesal del Reino de Nápoles, su reflexión desemboca en una teoría procesalista de carácter garantista. Los principios sobre los cuales tal teoría se articula son: el principio de legalidad del proceso, el principio de la imparcialidad del juez, el principio de la paridad de poderes entre acusación y defensa, el principio de contradicción, y el principio de la oralidad y de la publicidad de todo el procedimiento. De esta forma, Pagano intenta dar forma a un coherente sistema de garantías en el cual encontraban expresión y orden las razones políticas y las principales instancias de la llustración penal.

Palabras clave: garantías fundamentales del inculpado, proceso inquisitorio, proceso acusatorio, llustración penal.

ABSTRACT. Pagano's normative theory of criminal law shall be understood as part of the criminal enlightened tradition that comprehends Montesquieu's and Beccaria's thought. From the influence of this authors Pagano develops what, in his opinion, is the general framework for a modern criminal process based on the fundamental guaranties of the accused. The criticism that Pagano addresses to the inquisitorial process is not only based on the lack of guaranties -the main critic from the supporters of the accusatorial model- but also it challenges the defenders of the inquisitorial model in their own ground: the repressive interpellation. Still, Pagano's thesis goes far beyond his claim against the procedural system in the Reign of Naples, since he provides a more complex procedural garantist theory. The principles underlying Pagano's theory are: the principle of due process of law, the principle of impartiality, the principle of equal concern and respect of parties alike, the principle of contradictio and the principle of orality and publicity of the process. In such a way, Pagano intends to provide the basis for a coherent system of guaranties through which the political thought of the criminal enlightenment finds expression.

Keywords: fundamental guaranties of the accused, inquisitorial process, accusatorial process, criminal enlightenment. 


\section{INTRODUCCIÓN}

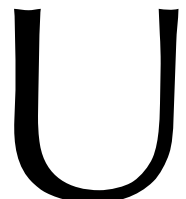

n año antes de subir al patíbulo de la Piazza del Mercato de Nápoles, condenado a muerte por su participación en el gobierno de la República napolitana de 1799, Francesco Mario PAgANO se encontraba desterrado en Milán, capital de la joven República cisalpina, al ser perseguido por la monarquía borbónica como opositor político. Allí, el 18 de diciembre de 1798, tras una orden de expulsión emitida por la autoridad policial, dirigió una vibrante protesta por escrito a los miembros del Consiglio dei Juniori, que no dudaron en sumarse unitariamente a su defensa ${ }^{1}$ :

¡Ciudadanos Legisladores! Me veo forzado a solicitarles el derecho de asilo y protección que su Constitución me concede y que, sin embargo, me ha sido negado. Veinte años de cátedra en Derecho público en Nápoles, durante los cuales he procurado instilar la teoría y los sentimientos de libertad en la mente y en el corazón de los jóvenes; los Ensayos políticos, publicados hace dieciséis años, en los que desarrollé los principios de la democracia y de los derechos del hombre; el Proceso Penal, que fue traducido al francés y presentado ante la Asamblea Constituyente recibiendo mención honorífica en el proceso verbal en agosto de 1789 [...]; veintinueve meses de cárcel padecidos en Nápoles durante los que se me arrebató la preciada libertad; el cargo de magistrado y el sacrificio de una considerable fortuna al dedicarme a esta gran causa; la huida, con apuros lograda, nada más pisar suelo libre; el cordial acogimiento que me ofreció la República romana; la invitación por parte del Ministro del Interior para ocupar la cátedra de Derecho público, que acepté renunciando a los correspondientes honorarios; la fuga de aquella República con las conocidas calamidades. Todos estos parecíanme títulos suficientes como para que no se me hubiera impedido disfrutar del derecho de asilo que había solicitado en este suelo ${ }^{2}$.

Presentándose a sí mismo con estas palabras, PAGANO encuadraba toda su actividad intelectual desde los años ochenta en el marco de un fuerte compromiso político en pro de la libertad. También su obra como jurista formaba parte de esta lucha civil: no por casualidad, junto a los Ensayos políticos, testimonio de sus ideales republicanos, él recordaba —en el discurso apologético recién citado- su Consideraciones sobre el proceso penal ${ }^{3}$ y sus lecciones universitarias de Derecho penal, por entonces inéditas pero que circulaban en forma de manuscrito y que fueron publicadas póstumamente en dos monografías, tituladas respectivamente Principios del Código Penal y Lógica de los probables ${ }^{4}$.

1 Para la biografía de PAGAnO véase SOLARI, 1963: «Della vita e delle opere di Francesco Mario Pagano», en íd., Studi su F. M. Pagano, ed. de L. FIRPO, Turín: Giappichelli, y VenturI, 1962: «Francesco Mario Pagano. Nota introductiva», en Illuministi italiani, t. V, Riformatori napoletani, Milán-Nápoles: Ricciardi, 1997, vol. II, t. II, pp. 783-833.

${ }_{2}$ Cfr. FIORELl, 1917: «Mario Pagano esule a Milano», en Archivio Storico Lombardo, XLIV, 15-16: pp. 1-2.

3 Pagano, 1787: Considerazioni sul processo criminale, Napoli: Raimondi. La edición por la que se cita en el presente trabajo es la edición milanesa de Tosi y NoBILE, de 1801 [en adelante, CSP].

4 Pagano, 1803: Principi del codice penale, Milán: Agnello Nobile [en adelante, PCP (1)]. El número entre paréntesis sirve para distinguir esta edición de la edición napolitana, basada en un manuscrito distinto, publicada en Sangiacomo en el año 1806 (cfr. SOLARI, G., 1936: Le opere di Mario Pagano: ricerche bibliografiche, Turín: R. Accademia delle Scienze, pp. 46-54). Para la edición napoliana se empleará aquí la sigla PCP (2), que se refiere al texto contenido en el volumen PAGANO, 2000: Giustizia criminale e libertà civile, Roma: Editori Riuniti, pp. 45-119. II. PAGANO, 1806: Logica de’ probabili applicata a' giudizi criminali, Milano: Agnello Nobile [en adelante, $L P(1)$. El número entre paréntesis sirve para distinguir esta edición de la edición napolita- 
Estas tres obras constituyen conjuntamente el punto de referencia principal para el estudio del pensamiento penal de PAGANO. En las Consideraziones, elabora una reconstrucción del sistema procesal vigente, criticándolo a la luz de los principios de garantía fundamentales expresados en la cultura ilustrada. La Lógica completa la doctrina procesalista paganiana en lo tocante a la disciplina y teoría de la prueba. Los Principios, por su parte, tratan problemas relativos al Derecho penal sustantivo5.

Mientras que las Consideraziones es una obra concebida como instrumento de lucha política - en la cual las ideas de PAGANO se colocan en abierta polémica con la realidad del ordenamiento-, los Principios y la Lógica conforman un manual universitario destinado a los estudiantes de Derecho penal, donde la actitud crítica en relación con el Derecho positivo es, por fuerza de las circunstancias, mucho más sutil. Lo cual no significa que, en el fondo, sea menos radical: son más bien los tonos y la estrategia que la crítica debe seguir para adaptarse a un contexto diferente. Para darle fuerza a sus tesis, constantemente críticas con la praxis jurídica, PAGANO recurre continuamente a la fuerza autoritativa del Derecho romano, del cual toma únicamente aquellos principios que están en sintonía con las instancias iuspolíticas de la Ilustración, colocándolos a modo de bisagras en la reconstrucción racional del ordenamiento. Así pues, desde la cátedra universitaria PAGANO no dicta lecciones de dogmática jurídica, sino que profesa una teoría normativa del Derecho penal.

$\mathrm{Al}$ análisis de la dimensión procesal de esta teoría y a su ubicación en su contexto cultural están dedicadas las páginas que siguen.

\section{PAGANO Y LA CENTRALIDAD POLÍTICA DEL PROBLEMA PENAL}

«En este siglo, la antorcha de la filosofía comenzó a iluminar las tinieblas del foro. El autor de Del espiritu de las leyes, a saber, el célebre Presidente de MONTESQUIEU, fue el primero en dirigir la mirada filosófica sobre la jurisprudencia penal. El célebre Marqués DE BECCARIA en su libro De los delitos y de las penas, muy conocido en Europa, sometió ex proposito a examen muchas doctrinas ciegamente seguidas en el foro. Una multitud de escritores siguieron los pasos de estos valientes hombres» ${ }^{6}$.

Con estas palabras PAGANO introducía a los estudiantes del ateneo napolitano su curso de «Instituciones penales». Las palabras resultaban inequívocas: el curso se iniciaba en la senda de ruptura con la cultura jurídica tradicional y con la penalística forense.

Más que la referencia crítica a la «doctrina ciegamente seguida en el foro», era la referencia a MONTESQUIEU y a BECCARIA — nombres estandarte de la Ilustración pe-

na, basada en un manuscrito distinto, publicada en Sangiacomo en el año 1806 con el título Logica de’ probabili per servire di teoria alle pruove nei Giudizi criminali. Para esta versión se empleará aquí la sigla $L P(2)$, que se refiere al texto contenido en el volumen PAGANO, 2000: Giustizia criminale e libertà civile, Roma: Editori Riuniti, pp. 121-199. Tanto la edición milanesa como la edición napolitana de la Logica se basan en manuscritos más completos que el publicado con el título Teoria delle prove como apéndice a la primera edición de los Principi del codice penale (Milán: Nobile, 1803: pp. 92-176) (cfr. Solari, G.: Le opere di Mario Pagano, cit., pp. 46-54).

${ }^{5}$ Sobre el pensamiento penal de PAGANO véase también el importante trabajo de PALOMBI, E., 1979: Mario Pagano alle origini della scienza penalistica del secolo XIX, Napoli: Giannini.

${ }^{6} P C P(1)$, «Introducción», p. 9. 
nal ${ }^{7}$ - lo que ponía de manifiesto la dirección innovadora adoptada por PAGANO. Y la mención a esa «multitud de escritores» que les siguieron, aunque no hacía justicia a quienes destacaron entre esa multitud (sorprende la omisión de un merecido reconocimiento a FILANGIERI), colocaba oportunamente la reflexión paganiana en el contexto de ese fermento de ideas y de proyectos que en la segunda mitad del siglo XVIII había sometido a análisis el modelo penal dominante en los Estados de la Europa continental ${ }^{8}$.

Desde que BECCARIA, en 1794, había relanzado las tesis garantistas y humanitarias de MONTESQUIEU y otras de semejante inspiración, agrupándolas en un breve opúsculo que rápidamente recorrió todos los países de Europa, la cuestión penal se había convertido en un tema central del debate público ${ }^{9}$. Los frutos prácticos de este movimiento ya eran visibles en los países gobernados por los soberanos más receptivos a las propuestas reformadoras. Pero estos eran casos excepcionales ${ }^{10}$. En otros lugares se seguía sembrando: allí donde los tiempos de la cosecha casi coincidirían con la estación revolucionaria. $\mathrm{Y}$ es que, efectivamente, los principios y argumentos que en el ambiente ilustrado alimentaban el debate sobre las penas eran auténticas semillas de revolución.

El carácter político del Derecho penal fue asumido y representado en toda su plenitud, y la crítica escarbó hasta las raíces de la estructura tradicional del poder. Sustraído el hombre al orden preestablecido, desigual y autoritario de las jerarquías de status; descubierto el individuo como artífice racional del mundo político; declarados inalienables sus derechos naturales y elevados esos derechos a norma de reconocimiento del poder legítimo... de esta forma, el pensamiento ilustrado sometía a examen el problema de la legislación penal como piedra de toque para caracterizar al poder político ${ }^{11}$.

A quien, al pensar en la política, asumía el punto de vista del sujeto portador de derechos intangibles, sobre todo la vida y la libertad, la justicia penal se le revelaba como un factor crítico y crucial. ¿Podía justificarse un poder que conculcara tales derechos? ¿Quién podría ejercerlo? ¿Contra quién y dentro de qué límites podría entenderse legítima su acción? ${ }^{12}$. En ningún otro momento de la vida social el poder se manifestaba en formas más peligrosas para el individuo que en el acto de la represión penal; ese era el terreno en el que la presencia de la autoridad política se mostraba más invasiva. Y sin embargo la ley penal era necesaria. ¿Cómo podía haber libertad y seguridad del sujeto, seguridad de la libertad, sin una norma imperativa provista de sanción?

${ }^{7}$ La literatura sobre el pensamiento penal de MONTESQUIEU y de BECCARIA es vastísima. Véase, sobre todo, DeRATHÉ, 1966: «Le droit de punir chez Montesquieu, Beccaria et Voltaire», en Atti del Convegno Internazionale su Cesare Beccaria, Turín: Accademia delle Scienze, pp. 85-100; CATTANEO, 1974: La filosofia della pena nei secoli XVII e XVIII, Ferrara: De Salvia, pp. 107-128; TARELLO, G., 1997: Storia della cultura giuridica moderna. Assolutismo e codificazione (1976), Bologna: Il Mulino, pp. 415-478.

${ }^{8}$ Véase la rica antología de documentos editados por VentuRI en BeCCARIA, 1764: Dei delitti e delle pene, ed. de VentuRI, 1964:, Turín: Einaudi, 2003, pp. 165-650; así como la importante «Introducción» del mismo VENTURI (ibid, pp. VI-XXXVI). Para citar la obra de BECCARIA se hará referencia a esta edición.

${ }^{9}$ Cfr. VenTURI, 1970: Utopia e riforma nell'illuminismo, Turín: Einaudi, 1978, pp. 119-143.

${ }^{10}$ Para un amplio panorama sobre las políticas penales de la segunda mitad del siglo XVIII véase La «Leopoldina». Criminalità e giustizia criminale nelle riforme del Settecento europeo, ed. de L. BERLINGUER, Siena: Università degli Studi di Siena, 1986.

${ }^{11}$ Cfr. COSTA, 1999: Civitas. Storia della cittadinanza in Europa, vol. 1. Dalla civiltà comunale al Settecento, Roma-Bari: Laterza, pp. 433-440.

${ }^{12}$ En el conjunto de estas preguntas TARELLO hace consistir «el "problema penal" en el siglo XVIII»: cfr. TARELLO, 1976: 383. 
El Derecho penal se configuraba así, a la luz de esos interrogantes y de esa conciencia, como el eje principal del orden civil y el instrumento indispensable, aunque delicadísimo, para la construcción de las barreras de protección de la libertad del individuo ${ }^{13}$.

La toma de conciencia sobre la importancia «constitucional» de la legislación penal es ya clara en MONTESQUIEU: habla por sí mismo el título del duodécimo libro de su obra principal, «De las leyes que determinan la libertad política en su relación con el ciudadano», en donde las leyes en cuestión son precisamente las «leyes penales» ${ }^{14}$. Dado que la libertad consiste en la seguridad de los propios derechos, y que por lo demás no puede prescindir nunca de la confianza subjetiva en esta seguridad, «de la bondad de las leyes penales depende principalmente la libertad del ciudadano» ${ }^{15}$. De esta manera, la «bondad» del Derecho penal venía a condicionar, en gran medida, la bondad del gobierno.

Desde tales premisas ha de entenderse que se desenvuelven las conversaciones entre BECCARIA, los hermanos Verri y Luigi LAMBERTENGHI, a través de las cuales se articula el célebre «librito» ${ }^{16}$ del Marqués ${ }^{17}$. De ahí el homenaje al «inmortal Presidente de Montesquieu» ${ }^{18}$ situado al comienzo de la obra: un explícito reconocimiento al mérito del pionero, que había señalizado el camino correcto con «huellas luminosas» ${ }^{19}$. La meta consistía en la definición del Derecho penal justo, o sea, el que respondiera a la doble exigencia de orden social y de libertad individual: la libertad no existe sin orden, pero el orden es ilegítimo si no asegura la libertad $\gg^{20}$.

La legislación penal vigente había fracasado en ambos frentes: no producía seguridad, porque no evitaba los delitos; y no garantizaba la libertad, porque pisoteaba los derechos. Emblemático, desde este punto de vista, era el empleo de la tortura como instrumento de investigación judicial: ¿Cuántos culpables evitaban la pena resistiendo a los tormentos? ¿Y cuántos inocentes, cediendo y confesando en falso, padecían el castigo por delitos nunca cometidos ${ }^{21}$ ? El sistema penal debía ser reformado en todos sus aspectos; tipos delictivos, clases de penas y el modelo procesal necesitaban de una reformulación integral sobre el dictado de los principios de una política destinada a fundarse en los derechos del individuo ${ }^{22}$.

Cuando escribía BECCARIA, todavía «poquísimos habían examinado y combatido la crueldad de las penas y la irregularidad de los procedimientos penales» ${ }^{23}$. Veinte años después, cuando PAGANO debutaba en la cátedra de Derecho penal, a pesar de que aque-

${ }_{13}$ Cfr. Cattaneo, 1974: pp. I-IX, y Costa, 1999: pp. 433-440.

${ }^{14}$ Secondat de Montesquieu, C.-L. de, 1748: Lo Spirito delle leggi, ed. de R. Derathé, 1996: Milán: Rizzoli, lib. XII, cap. II, p. 342.

${ }^{15}$ Ibidem.

${ }^{16}$ Manzoni, 1842: Storia della Colonna Infame, Milán: BUR, 1961: p. 56.

${ }_{17}$ Véase el testimonio de P. VerRI en CASATI, 1879: Lettere e scritti inediti di Pietro e Alessandro Verri, Milán: Galli, vol. I, p. 183.

${ }^{18}$ BECCARIA, 1774: 10.

19 Ibidem.

${ }^{20}$ Cfr. ibidem, I, p. 11.

${ }^{21}$ Cfr. ibidem, XVI, p. 38.

${ }^{22}$ COSTA, 1999: 434-440.

23 BECCARIA, 1774: «Introducción», p. 10. 
llos «pocos» se habían convertido en una «multitud», todavía permanecían «las profundas heridas que enfermaban y minaban el universal sistema penal europeo» ${ }^{24}$. Por eso, la lucha contra la iniquidad, la irracionalidad y la inhumanidad del ordenamiento vigente debía continuar. Y PAGANO recogía el testimonio de los «Filósofos Filántropos» ${ }^{25}$ con manifiesto orgullo y firme conciencia: «me atrevo por tanto a atravesar las tinieblas del foro con la antorcha de la filosofía; intrépidamente [...] me atrevo a criticar las opiniones reinantes, consagradas por la pluma de los juristas y adoptadas a veces por la venerable autoridad de las leyes; y me atrevo asimismo a proponer la reforma» ${ }^{26}$.

Así, Pagano lanzaba su desafío contra todos «aquellos que, usando la memoria por razón, y la autoridad por evidencia en las decisiones de Afflitto y de Riccio, busca[ba]n los principios de la razón pública» ${ }^{27}$. Esos principios no se hallaban en la tradición sino que se extraían de otro lado y eran hechos valer en la realidad. Debían convertirse en Derecho positivo y sustituir a la legislación existente y a las prácticas enraizadas en la administración de justicia. La empresa era enorme; se trataba de «derribar un coloso que el prejuicio y la opinión [habían] erigido durante muchos siglos» ${ }^{28}$. Era inevitable la colisión contra los «intereses privados de muchos» ${ }^{29}$; previsible la resistencia de los «esclavos del hábito y del ejemplo» ${ }^{30}$. Las relaciones de fuerza no eran favorables, ciertamente; pero lo que estaba en juego era demasiado importante como para renunciar al combate. En efecto: se trataba de la afirmación de un orden iuspolítico orientado a la salvaguarda de los derechos del individuo.

Para Pagano, todavía más que para MontesQuieu, el problema penal es el problema constitucional por excelencia. La legislación penal es el principal indicador de la calidad de un gobierno, en cuanto que a través de ella se lee inmediatamente la estructura del poder y la esfera del individuo. Su conformación incide directamente sobre la libertad civil, ya sea protegiéndola o, por el contrario, aniquilándola ${ }^{31}$.

Sólo la ley, efectivamente, permite el paso de la condición de conflicto entre los individuos al orden político. En ausencia de la ley, el hombre es libre de hacer uso de sus propias facultades naturales, pero tal libertad — como había enseñado (lockeanamente) BECCARIA—, «se vuelve inútil ante la incertidumbre de conservarla» ${ }^{32}$. Si nuestras acciones son reguladas exclusivamente a partir de nuestros propios impulsos y apetitos, cada hombre representa una constante amenaza para sus semejantes: la libertad sin ley posee el impulso egoísta de la opresión. De ahí la necesidad de la ley positiva, fiel copia de la ley natural, que interviene para limitar la libertad de cada uno y hacerla compatible con la libertad de todos. Tal es la libertad civil, que consiste en el ejercicio de nuestros derechos, en definitiva, en el uso de nuestras facultades físicas y morales regido por el principio del alterum non laedere ${ }^{33}$.

\footnotetext{
${ }^{24}$ Carta de Pagano Al Regio Consigliere Signor Cavaliere D. Luigi Medici de' Principi d'Ottiano, en CSP, p. IV.

${ }^{25} \mathrm{PCP}(2)$, «Al lettore», p. 5.

${ }^{26}$ CSP, «Al Regio Consigliere», p. IV.

${ }^{27}$ Ibidem, p. III.

${ }^{28}$ Ibidem.

${ }^{29}$ Ibidem.

${ }^{30}$ Ibidem.

${ }^{31}$ Cfr. ibidem, «Introducción», pp. 1-3.

32 BECCARIA, 1774: I, p. 11.

${ }^{33}$ Cfr. CSP, cap. I, pp. 5-10.
} 
La ley, por tanto, es garantía de la libertad. Y la garantía de la ley es la pena, el arma que la prohibición normativa amenaza con utilizar frente a los transgresores. He ahí por qué la legislación penal es la tabla que soporta la libertad civil ${ }^{34}$. Una tabla frágil, sin embargo; que puede fácilmente quebrarse poniendo con ello en riesgo aquello que debería sostener.

PAGANO señala los dos puntos de fractura trágicamente revelados por la observación de la realidad. El primero es la ineficacia de la ley. Allí donde la prohibición no es respetada y la sanción no castiga al trasgresor, se menoscaba la seguridad de nuestros derechos: «Donde los delitos quedan impunes, ahí reina siempre la indómita licencia; ahí [...] el ciudadano puede ser impunemente privado de sus derechos; ahí no se goza de libertad, no se conoce la seguridad, no se disfruta de la tranquilidad» ${ }^{35}$. El segundo punto se refiere al arbitrio represivo de la justicia penal. El poder, que debería actuar como custodio de los derechos de los individuos, defendiéndolos de las ofensas de otros, puede desviarse de esa finalidad asumiendo formas y modalidades de acción dañinas contra la libertad: «si para indagar y castigar los delitos se sueltan en exceso las manos del juez, donde él mucho se atreva e ilimitadamente actúe; si la ley suministra el medio a través del cual o el ciego celo o la maldad cubierta por el manto de lo justo pueda atentar contra los derechos del ciudadano [...], la libertad y la inocencia, las dos grandes deidades que las leyes deben respetar sobre todas las cosas, nunca estarán aseguradas» ${ }^{36}$. La denuncia de PAGANO se dirige contra el sistema penal vigente, afectado de esos dos nocivos liberticidas que, al sumarse el uno al otro, multiplican sus devastadores efectos.

FILANGIERI había considerado en los mismos términos la cuestión de la justicia penal en la introducción al libro tercero de su monumental obra ${ }^{37}$ : «en la legislación penal -había escrito- el temor [...] del malvado debe ser combinado con la seguridad del inocente» ${ }^{38}$. Sin embargo un abismo separaba el deber ser de la realidad: «nosotros podemos afirmar con certeza que no hay delito, por manifiesto que sea, que no pueda, bajo el auspicio de este complicado y erróneo método de inquisición, quedar impune; y no hay inocencia, por conocida que sea, que tenga asegurada su tranquilidad y su paz» ${ }^{39}$.

A los ojos de ambos autores la obra de reflexión y de renovación del ordenamiento penal debía comenzar por la reforma del proceso: un agujero negro en el que desaparecían todos los derechos subjetivos. Una «mezcla monstruosa - denunciaba FILANGIERI, influido por el célebre incipit del De los delitos- de los principios de la jurisprudencia romana con los principios, en parte abolidos y en parte existentes, de la legislación de los bárbaros, del sistema feudal, y de las leyes canónicas; máximas, algunas de ellas, contrarias a la libertad del hombre y que destruían los derechos más pre-

34 Cfr. ibidem.

35 CSP, cap. V, p. 19.

36 CSP, cap. II, pp. 10-11.

37 FILANGIERI, 2003: La Scienza della legislazione (1780-1791), Nápoles: Grimaldi [reimpresión anastática de la edición parisina de C. DERRIEY, 1853]. El libro tercero de la obra, Delle leggi criminali, aparecido en el año 1783, está dividido en dos partes; la primera se titula Della procedura y la segunda De' delitti e delle pene.

38 Ibidem, lib. III, parte I, cap. I, p. 118.

39 Ibidem, pp. 118-119. 
ciados del ciudadano» ${ }^{40}$. Este monstruo jurídico, observaba PAGANO, producía una «insidiosa red, en la cual los pequeños y pobres ciudadanos son detenidos, mientras que los grandes y potentados culpables habiendo violado las reglas quedan impunes» ${ }^{41}$.

Se necesitaba reconstruir el procedimiento penal en todas y cada una de sus partes teniendo en cuenta su función civil: la protección de la libertad. Cada regla y cada institución debían ser valoradas a la luz de la doble exigencia del castigo del culpable y de la máxima garantía al inocente. Demasiados eran los resortes legales que, sin servir de escudo a la inocencia, permitían al reo sustraerse a la pena: formalidades no garantistas, sino meramente dilatorias, generadoras de impunidad. Demasiado escasas, casi inexistentes, las normas adecuadas para proteger al imputado inocente de ser injustamente castigado ${ }^{42}$. Había que abolir aquéllos y establecer éstas, circunscribiendo estrictamente, por vía legal, el poder discrecional de los magistrados, con el fin de despojar, en la medida de lo posible, «al inocente de cualquier temor, al culpable de toda esperanza, y a los jueces de cualquier arbitrio» ${ }^{43}$.

\section{EL PROCESO: LA TUTELA DE LA INOCENCIA Y LA GARANTÍA DE LA VERDAD}

Movido por la toma de conciencia - madurada sobre la lectura de MONTESQUIEU y agudizada por el panorama de degradación del sistema judicial del reino de Nápoles- de que «el proceso penal [...] es el custodio de la libertad, la trinchera contra la prepotencia, el indicador cierto de la felicidad nacional» ${ }^{44}$, PAGANO traza las líneas fundamentales de un proceso penal moderno, planteando las garantías fundamentales del imputado no sólo como irrenunciables instrumentos de tutela de la libertad, sino como el mejor método de obtención de la verdad.

También FiLANGIERI, en su Ciencia de la legislación, había visto en el proceso penal la articulación fundamental de la organización del poder en relación con los sujetos. Con ello evidenciaba los intolerables defectos del sistema vigente, señalaba las dificultades de la tarea de «reparación» y, al mismo tiempo, se lamentaba de la escasez e inadecuación de los análisis y de las propuestas reformadoras ${ }^{45}$ : «La filosofía se ha detenido en algunos de sus elementos más manifiestamente viciosos, pero todavía no ha alcanzado a ver la máquina entera» ${ }^{46}$.

En efecto, tanto MONTESQUIEU como BECCARIA habían privilegiado la parte sustantiva de la legislación penal frente a la procesal. Si sus respuestas a las preguntas

\footnotetext{
${ }^{40}$ Ibidem, p. 118.

${ }^{41}$ CSP, cap. VI, p. 25.

${ }^{42}$ Cfr. CSP, cap. III-V, pp. 12-21.

${ }^{43}$ FILANGIERI, 2003: lib. III, parte I, cap. I, p. 119.

${ }^{44}$ CSP, «Introducción», p. 3.

$45 \mathrm{El}$ procedimiento es considerado por FILANGIERI como la «parte» de la legislación penal que resulta ser «la más difícil de reformar y la más interesante que tratar» (FILANGIERI, 2003: lib. III, parte I, cap. I, p. 119).

46 Ibidem. Para el debate sobre el proceso penal en la segunda mitad del siglo XVIII, véase DEZZA: Note su accusa e inquisizione, cit., pp. 185-239, que analiza las posturas de Luigi CREMANI, Filippo Maria RENAZZI, Alberto DE SimOni, FILANGIERI, y PAGANO (en particular, a las ideas filangierianas están dedicadas las pp. 209 -
} 223). 
sobre «qué prohibir» y «cómo castigar» habían sido claras, precisas y puntuales, llegando a proporcionar una sólida teoría normativa del Derecho penal, menos elaboradas, en cambio, se presentaban sus tesis relativas al problema del «cómo juzgar». No faltaba, ciertamente, la crítica al procedimiento de la época. Y de forma clara se presentaba también la formulación de los principios fundamentales de garantía en torno a los cuales habría de centrarse la dogmática penal posterior. Pero no se encontraba en el Espiritu de las leyes, y tampoco en De los delitos, lo que FILANGIERI y PAGANO afirmaban como indispensable: «un nuevo método» procesal que sustituyera «al antiguo» ${ }^{47}$.

BECCARIA sí había contrapuesto a un «proceso ofensivo», practicado «casi en todos los lugares de la Europa ilustrada», un proceso «informativo [...] muy poco practicado en los tribunales europeos» ${ }^{48}$. Contra el primero dirigía su crítica mientras que al segundo lo exaltaba como el «verdadero proceso» («el que la Razón ordena») 49. Pero los lineamientos del modelo propugnado no estaban definidos con detalle en un cuadro de conjunto. Y la verdad es que la adecuada comprensión de su punto de vista procesalista no se veía favorecida por la vinculación empírica que su propuesta tenía con el sistema «usado por el propio despotismo asiático en los casos fáciles e indiferentes» ${ }^{50}$, sistema que había enseñado MONTESQUIEU (y que de él había aprendido la mayoría de sus contemporáneos cultos) a propósito de las instituciones penales de los gobiernos despóticos ${ }^{51}$.

Para pensadores de una vasta cultura jurídica como FilangIERI y PAGANO, no era necesario buscar tan lejos (ni en un lugar tan improbable) la alternativa al procedimiento continental contemporáneo; más útiles que las inciertas indicaciones beccarianas eran las aceptadas sistematizaciones doctrinales de la tradición penalista del Derecho común, que distinguían dos modelos procesales, el inquisitivo y el acusatorio: vigente en Europa el primero, monumento de la experiencia judicial romana el segundo ${ }^{52}$.

Puesto a punto por la ciencia jurídica moderna con una finalidad puramente teórica, tal esquema dualista ya había sido explotado en su potencial crítico en los albores del siglo XVIII por el heredero más representativo de la tradición iusnaturalista del siglo XVII, Christian THOMAsIUs, quien en su disertación «de origine processus inquisitorii ${ }^{53}$ había montado un vigoroso primer asalto contra la inquisitio. TOMASIO cuestionó las instituciones de la inquisitio sobre la base de los «dictamina rectae rationis» ${ }^{54} \mathrm{y}$, por contra, ofreció una defensa de la accusatio fundada en su conformidad con el Derecho natural ${ }^{55}$.

${ }^{47}$ FILANGIERI, 2003: lib. III, parte I, cap. I, p. 119.

${ }^{48}$ BECCARIA, 1774: XVII, p. 46.

${ }^{49}$ Ibidem.

${ }^{50}$ Ibidem.

${ }^{51}$ Cfr. Montesquieu, 1748: lib. VI, pp. 221-243; lib. XII, pp. 341-366.

${ }^{52}$ Cfr. DeZZA, 1989: Accusa e inquisizione. Dal diritto comune ai codici contemporanei, Milán: Giuffrè.

53 Thomasius, 1711: Dissertatio de origine processus inquisitorii, Halle. La edición que aquí se cita se encuentra en Christianii Thomasii dissertetionum academicam varii imprimis iuridici argumenti tomus tertius, Halae Magdeburgicae, impensisi vid. Gebaueri et filii, 1777, pp. 421-443. Sobre la doctrina procesalista de TOMASIO véase DEZZA, 1989: 116-135.

${ }^{54}$ Ibidem, III, p. 422.

${ }^{55}$ Ibidem, p. 423. 
PagANO, setenta años después, explorará un sendero similar. La recepción de los modelos doctrinales le permitió individualizar inmediatamente los puntos de referencia históricos que eran útiles para la definición de su proyecto reformador, así como para la elaboración de su más amplia concepción procesalista; la cual, conviene subrayarlo, no se deduce únicamente del primero. Cuando la investigación sobre el pensamiento de PAGANO se limita a tomar en consideración su «Reforma del proceso penal $\rangle^{56}$, concebida de forma realista con vistas a una finalidad práctica inmediata, no logra captar en su integridad la teoría garantista orgánica y coherente que él articuló. Una adecuada reconstrucción de esa teoría ha de ser llevada a cabo, por el contrario, teniendo en cuenta todos los análisis de orden histórico, crítico y reconstructivo presentes en las Consideraciones.

En la orientación de su obra, PAGANO asume una perspectiva de tipo histórico y comparativo: su búsqueda de las reglas del proceso justo parte de la reconstrucción del iter procesal romano-republicano ${ }^{57} \mathrm{y}$ de la exposición de las instituciones del sistema procesal inglés ${ }^{58}$, del cual FiLANGIERI había obtenido también los elementos para su doctrina procesalista ${ }^{59}$.

El cuadro histórico de la accusatio romana es diseñado no sólo mediante el uso de las fuentes legislativas transmitidas por la compilación justinianea, sino también apoyándose en materiales judiciales y en obras historiográficas (CICERÓN y TÁCITO), siguiendo un modelo de matriz humanista, probablemente aprendido a través del estudio de Anton MATTHES ${ }^{60}$. El perfil del proceso inglés descansa en cambio en la lectura de BLACKSTONE ${ }^{61}$ y de DE LOLME ${ }^{62}$, cuyas obras, muy difundidas en la Europa del siglo XVIII, habían contribuido a acrecentar el (ya consolidado) mito ilustrado de Inglaterra.

Es precisamente al final del capítulo dedicado al sistema procesal inglés cuando PAGANO expresa un primer juicio claro a favor del modelo acusatorio: en el sistema inglés «es imposible la opresión, imposible que el juez de paz, los grandes y pequeños jurados, los ministros reales concurran todos en el mismo mal diseño» ${ }^{63}$. En cuanto a la evaluación negativa del proceso inquisitivo, esta ya se podía apreciar con nitidez incluso antes de ser formulada de forma explícita y motivada de manera rigurosa, en la reconstrucción histórica que PAGANO realiza sobre su origen y su evolución.

En contra de la opinión de TOMASIO, quien afirmaba que el origo processus inquisitorii debía remontarse al pontificado de Inocencio III y, en concreto, a las estrategias judiciales de represión antiherética practicadas en aquella época ${ }^{64}$, PAGANO sitúa el na-

${ }^{56}$ Cfr. CSP, cap. XXXII, pp. 158-168.

${ }^{57}$ Cfr. ibidem, VII, pp. 27-38.

${ }^{58}$ Cfr. ibidem, VIII, pp. 39-43.

${ }^{9}$ Cfr. FILANGIERI, 2003: lib. III, parte I, cap. I, p. 119.

${ }^{60}$ Matthes, 1644: De criminibus. Ad lib. XLVII et XLVIII Dig. Commentarius. Adiecta est brevis et succinta iuris municipalis interpretatio, Utrecht. Sobre la doctrina procesalista de MATTHES véase DeZZA, 1989: 106116. Pagano cita frecuentemente a MATTHES (italianizado como MATTEI), sobre todo en la Lógica, donde le define como «docto intérprete de las leyes, pero no agudo pensador» [LP (1), cap. III, p. 11].

${ }^{61}$ Blackstone, 1765-1769: Commentaires on the Laws of England, Oxford: Clarendon Press.

${ }^{62}$ De Lolme, 1771: Constitution de l'Angleterre, ou Etat du Gouvernement Anglais, comparé avec la forme républicaine et avec les autres monarchies de l'Europe, Amsterdam.

${ }^{63}$ CSP, cap. VIII, p. 42.

${ }^{64}$ Thomasius, 1711: LIII-LIV, pp. 442-443. 
cimiento de la inquisitio en la Roma imperial: «Un vulgar error, gallardamente sostenido por TOMASIO, hizo creer a muchos que era en el Derecho canónico donde se debía rastrear el origen del proceso inquisitivo. Sin embargo, aunque tal sistema fuese muy ampliado y promovido por el Derecho canónico, su introducción precede a ese Derecho, del mismo modo en que la tiránica política de la sospecha de los emperadores romanos precedió a la de los clérigos» ${ }^{65}$.

La génesis de la inquisición es pues asociada con una fase de tiranía política. Y su desarrollo, a peor, se vincula también con una situación histórica de grave crisis de la libertad civil: la «monarquía universal» ${ }^{66}$ de Inocencio III. Si el procedimiento imperial había transformado la condición del imputado, estableciéndose la encarcelación «con tan solo el informe inquisitivo» ${ }^{67}$, o sea, antes del eventual juicio de culpabilidad, el proceso canónico había hecho algo peor: había introducido el «procedimiento secreto y misterioso» ${ }^{68}$.

MATTHES y MONTESQUIEU habían encontrado la razón histórica del secretismo del procedimiento moderno, respectivamente, en un banal malentendido lingüístico cometido «por los primeros intérpretes bárbaros del Derecho romano» ${ }^{69} \mathrm{y}$ en la introducción de la escritura ${ }^{70}$. En oposición a ellos, PAGANO —esta vez siguiendo claramente a TOMASIO- considera el secreto judicial un legado del Derecho canónico: «Ese celo paternal —escribe con mordaz espíritu anticlerical— que inculcó nuestra santa religión a sus ministros, ese ministerio pastoral que debía esmerarse tanto en el cuidado de la grey que a ellos había sido encomendada, degeneró con el tiempo, como suele suceder, en el espíritu de la inquisición; armas [...] letales contra la inocencia. Cuando los ministros de la religión [...] hicieron uso de su poder temporal, transformaron la vigilancia pastoral en inquisitiva opresión» ${ }^{71}$.

Una vez puesta de manifiesto la matriz romano-canónica de las estructuras fundamentales de la inquisitio típicas del sistema procesal moderno, PAGANO asume inmediatamente una posición crítica frente a ella: es un método «terrible y feroz» ${ }^{72}$ que por su «natural e ingénita irregularidad» ${ }^{73}$ tiende a la «opresión» ${ }^{74}$.

La respuesta a la pregunta acerca de cuál es la realidad institucional que PAGANO intenta encuadrar bajo la fórmula de «proceso inquisitivo» se obtiene paulatinamente conforme avanza su estudio sobre «los desórdenes del sistema vigente» ${ }^{75}$, en el cual analiza los elementos constitutivos del procedimiento seguido por los tribunales napolitanos para juzgarlos a la luz de reglas procesales garantistas.

En esta investigación histórico-crítica cabe detectar la contraposición de dos modelos procesales antitéticos por su naturaleza y por sus características fundamentales:

\footnotetext{
${ }^{65}$ CSP, cap. IX, p. 46.

${ }_{66}$ Ibidem, cap. XII, p. 66.

${ }^{67}$ Ibidem, cap. XI, p. 62.

${ }_{68}$ Ibidem, cap. XII, p. 63.

${ }^{69}$ Ibidem.

${ }^{70}$ Cfr. Montesquieu, 1748: lib. XVIII, p. 753.

${ }^{71}$ CSP, cap. XII, p. 65.

72 Ibidem.

${ }^{73}$ Ibidem, cap. XIV, p. 71

${ }^{74}$ Ibidem, cap. XV, p. 76.

75 Ibidem, cap. XXX, p. 146.
} 
a) el rito inquisitivo, caracterizado por la presunción de culpabilidad del imputado, por la prisión preventiva, por el secreto y por la forma escrita de la instrucción probatoria, por la posición de inferioridad de la defensa respecto de la acusación, por la confusión entre la acusación y el juez; $b$ ) el rito acusatorio, fundado sobre la presunción de inocencia y la libertad personal del imputado, sobre la publicidad y sobre la oralidad, sobre la igualdad y sobre el principio de contradicción entre las partes, sobre el carácter de tercero y la imparcialidad del juez, sobre el carácter colegiado del órgano juzgador.

Cada uno de los elementos del sistema inquisitivo aparece a los ojos de PAGANO como una amenaza a (cuando no una negación directa de) la libertad civil, es decir, a la ratio misma que él atribuía al proceso. Por el contrario, los componentes del modelo acusatorio son concebidos como instrumentos de tutela de la inocencia y de garantía de la verdad.

En las líneas que siguen, se propone un repaso de los caracteres opuestos de los dos estilos procesales, tal y como vienen presentados en las Consideraciones, con el objetivo de definir los lineamientos del pensamiento procesalista de PAGANO y de indicar sobre puntos específicos sus estrechos vínculos con la reflexión ilustrada que le precede. La referencia a los ilustrados, por lo demás, no es expresa en PAGANO, quien se limita únicamente a una cita a FILANGIERI sobre el valor de la confesión ${ }^{76} \mathrm{y}$ a una remisión ge-

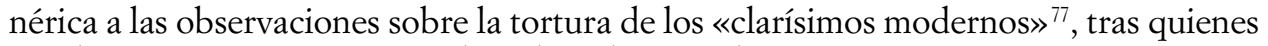
puede entreverse, por encima de todos, el rostro de BECCARIA.

a) Libertad personal vs. encarcelación «ante iudicium». Sobre la prisión preventiva se había manifestado ya, de forma crítica, BECCARIA, poniendo énfasis en la garantía de la presunción de inocencia y en el principio fundamental «nulla poena sine iudicio»: «la privación de libertad, siendo una pena — había escrito—, no puede preceder a la sentencia salvo cuando la necesidad lo exija» ${ }^{78}$. Tras él, FILANGIERI había denunciado con tono dramático la angustiosa condición del inocente relegado en prisión a la oscuridad de la imputación pendiente sobre su cabeza ${ }^{79}$, señalando con el dedo la indiferencia culpable de los soberanos que no corregían, ni siquiera frente a un escándalo tan epatante, «sus bárbaras leyes» ${ }^{80}$. Por su parte, PAGANO, también hombre del foro, y por tanto testigo directo del funcionamiento de una institución procesal abiertamente contrapuesta a las garantías de la libertad personal, deplora la «larga y penosa prisión, más grave a veces que la pena misma por el delito» ${ }^{81}$ del cual el detenido, en espera de juicio, es considerado sospechoso; y al considerar las situaciones de necesidad que pudieran ser una justificación, exalta el habeas corpus inglés como «sostén y base de la libertad británica» ${ }^{82}$.

b) Publicidad vs. secreto. PAgAnO también coincide con los «padres» de la Ilustración penal en la batalla contra el secreto inquisitivo: «públicos sean los juicios, y públicas las pruebas del delito» ${ }^{83}$, había reclamado BECCARIA, quien veía en la transparen-

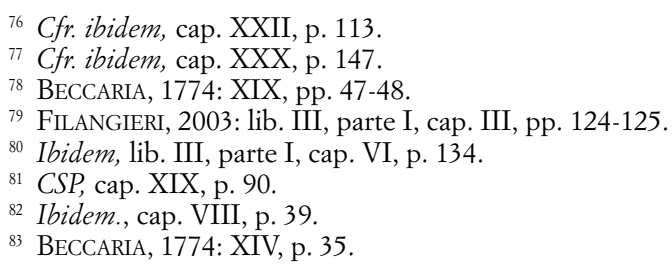


cia del poder un freno a la arbitrariedad. FILANGIERI había denunciado el «misterioso y arbitrario secreto» que «acompaña[ba] a los primeros y más interesantes pasos [...] del procedimiento» ${ }^{84}$. La crítica de PAGANO también se dirige contra el «bárbaro monstruo del insidioso arcano, que se introduce en el templo de la justicia para expulsar a esa reina de su propio trono» ${ }^{85}$. Él observa en el «taciturno e insidioso secretismo» un «misterio dañino» ${ }^{86}$ que perjudica la situación procesal de la defensa al privarla del conocimiento de la acusación y de los elementos de prueba y que, en consecuencia, pone en riesgo la inocencia.

c) Oralidad vs. escritura. PAGANO también pone en tela de juicio la instrucción escrita como base del juicio, pues la considera incompatible con la búsqueda de la verdad, a la que ha de orientarse el proceso. A las testificales por escrito, afirma, no debería dárseles ningún valor: la escritura «está muerta» y «no responde a nuestras dudas» ${ }^{87}$. Sólo la audiencia directa de los testigos permite a los jueces formarse una opinión sobre la verosimilitud de los hechos relatados: los gestos, los tonos, el comportamiento, el estado de ánimo del declarante contribuyen a conferir significado a sus deposiciones. Además, como razón para descalificar totalmente cualquier sentencia que se base en declaraciones escritas, PAGANO defiende el principio de método probatorio según el cual cuando el inquisidor que instruye el proceso transcribe en un documento los diversos testimonios, en realidad eso no es más que «un solo testimonio que da fe del dicho de otros» ${ }^{88}$.

d) Igualdad de las partes vs. superioridad de la acusación. A juicio de PAGANO, tanto la encarcelación ante iudicium como la inquisición secreta conducían a establecer, desde las fases iniciales del proceso, un fortísimo desequilibrio entre las partes: «el acusador — denuncia PAGANO- tiene una clara ventaja sobre el acusado» ${ }^{89}$. La instrucción probatoria, de hecho, no tomaba en consideración más que los datos y los testimonios a favor de la hipótesis acusatoria, organizándolos en una representación monolítica de los hechos, centrada en el punto de vista unilateral del inquisidor: «como si se tratara -ironiza amargamente PAGANO — de un poema reglado compuesto por él mismo» ${ }^{90}$. De esta forma, advierte, «el acusador [...] puede tejerle una red mortal a la inocencia» ${ }^{91}$. Y, si durante la fabricación de este «edificio funesto» ${ }^{92}$, cubierta por el «misterio dañino» ${ }^{93}$, el acusado se encuentra totalmente inerme, también una vez que se le ha puesto al corriente de la acusación sus facultades de defensa quedan reducidas al mínimo. El acusado, de hecho, asiste al juramento de los testigos sin conocer las declaraciones y sin posibilidad de confrontarlas. Y aun pudiendo presentar a su vez testigos y pruebas en contrario, no puede contrarrestar con ellas el resultado del proceso: «Por todos es bien sabido —escribe PAGANO— ese axioma del foro [...] según el cual las defensas se escriben pero nunca se leen» ${ }^{94}$.

\footnotetext{
${ }^{84}$ FILANGIERI, 2003: lib. III, parte I, cap. III, p. 124.

${ }^{85}$ CSP, cap. XI, p. 62.

${ }^{86}$ Ibidem.

${ }^{87}$ Ibidem, cap. XXVIII, p. 138.

${ }^{88}$ Ibidem, cap. XXI, p. 104.

${ }^{89}$ Ibidem, cap. XXVII, p. 84.

${ }^{90}$ Ibidem, cap. XIX, p. 89.

${ }^{91}$ Ibidem, cap.XVII, pp. 84-85.

92 Ibidem, cap. XVII, p. 84.

93 Ibidem, cap. XI, p. 62.

${ }^{94}$ Ibidem, cap. XXIX, p. 141.
} 
Como remedio a esta situación, FILANGIERI, además de reivindicar como garantía del reo «todos los medios posibles de defensa» ${ }^{95}$, había imaginado la instauración de un «magistrado defensor» ${ }^{96}$. PAGANO, en la misma línea, rechaza las estructuras inquisitivas, elevando a norma del justo proceso el principio según el cual «la condición del acusador y del acusado debe ser igual» ${ }^{97}$. El modelo histórico de referencia es siempre el proceso romano republicano, fundado sobre la igualdad de las partes y sobre el contradictorio como técnica de verificación probatoria: «Cada uno presentaba sus testigos, los documentos, los elogios de la comunidad, interrogaba e impugnaba los testimonios de la parte contraria» ${ }^{98}$. No existe juicio legítimo, según PAGANO, sin contradictorio; se trata de una garantía procesal insustituible porque, como escribe en la Lógica, «la confrontación es la piedra de toque de la verdad; y donde el sistema de juicios penales desconoce la contradicción, el azar, más que la verdad, dirige las sentencias de los jueces» ${ }^{99}$.

e) El juez como tercero vs. el Juez-inquisidor. El rito acusatorio defendido por PAGANO es un proceso de partes configurado sobre el postulado del juez como tercero. La Ilustración jurídica, a partir de un «precursor» como TOMASIO, había centrado la batalla contra la inquisitio en el terreno de la posición institucional del juez ${ }^{100}$. Desde esta perspectiva, el proceso vigente se mostraba como intrínsecamente injusto: «He visto -había escrito FILANGIERI- que un sistema procesal en el cual el juez debe hacer las veces de acusador es en sí mismo vicioso» ${ }^{101}$. Y antes que él BECCARIA ya había puesto en el banquillo de los acusados «al juez [...] enemigo del reo» que «no busca la verdad del hecho, sino que busca en el prisionero el delito» ${ }^{102}$. Su ideal, por el contrario, era el de un juez «neutral investigador de la verdad» ${ }^{103}$. Para PAGANO, la separación entre el juez y la acusación es el requisito previo de la legitimidad del juicio, a cuya luz resultaba inaceptable el sistema aplicado en Nápoles, como en el resto de Europa, en el que «se confundían juntas dos funciones opuestas» ${ }^{104}$. La posición institucional del juez debe ser, afirma él, super partes y perfectamente equidistante de la acusación y de la defensa: «El juez es el medio entre dos litigantes» ${ }^{105}$. A la relación vertical y dual juez-imputado propia del estilo inquisitivo, PAGANO contrapone la estructura triangular del proceso acusatorio, con el órgano juzgador en el vértice y a igual distancia del vértice, sobre el mismo plano, las partes: «El acusador y el reo suministran los datos, los hechos, las conjeturas, todo ello materia del juicio»; el juez «compara las razones opuestas y contrarias, las sopesa, y después juzga» ${ }^{106}$.

La reflexión paganiana en torno a la figura del juez no se limita a establecer este dato institucional, porque no son únicamente «institucionales» las condiciones de la imparcialidad del juicio. Es también decisiva la actitud subjetiva: la «indiferencia del

\footnotetext{
${ }_{95}$ FILANGIERI, 2003: lib. III, parte I, cap. XX, p. 181.

${ }^{6}$ Ibidem, p. 182.

${ }^{7}$ CSP, cap. XVII, p. 84.

${ }^{8}$ Ibidem, cap. VII, p. 36.

${ }^{99}$ LP (1), cap. IX, p. 31.

100 Thomasius, 1711: VI, p. 424.

101 Filangieri, 2000: lib. III, parte I, cap. V, p. 131.

102 BECCARIA, 1774: XVII, p. 46.

103 Ibidem, p. 45.

${ }^{104}$ CSP, cap. XIX, p. 95.

105 Ibidem.

106 Ibidem.
} 
juez» ${ }^{107}$ frente a las personas del proceso. Actitud que sólo estas últimas están en condiciones de, y por tanto tienen el derecho a, valorar. En particular, ese derecho - sostiene PAGANO — no se le puede negar al imputado, porque «quien debe ser juzgado, o por un juez enemigo suyo, o favorable a su contrario, nunca estará seguro ni confiará en la ley» ${ }^{108}$. Por esta razón, PAGANO insiste en el valor garantista de la libre recusación, ya puesto de manifiesto por MONTESQUIEU ${ }^{109}$ y por BECCARIA ${ }^{110}$. La experiencia romana y la inglesa se manifiestan una vez más en su visión procesal, igual que, sobre el mismo asunto, habían influido en la reflexión de FILANGIERI ${ }^{111}$. Los dos ilustrados coincidían en valorar negativamente la institución, entonces vigente, de la recusación motivada. Sobre todo —objeta PAGANO- es casi siempre imposible para el acusado probar la fundamentación de su propia sospecha de parcialidad del juez ${ }^{112}$; en segundo lugar, ambos autores señalan que lo más frecuente es que prevalezca un espíritu corporativista y que rara vez ocurre que los miembros de un tribunal colegiado se pronuncien en contra de un colega ${ }^{113}$; por último, observa FILANGIERI, la recusación intentada pero no aceptada convierte a quien a los ojos del imputado era un «juez dudoso» en un juez «con seguridad enemigo» ${ }^{114}$. La recusabilidad de los jueces debe estar, por tanto, totalmente a disposición de los acusados con el fin de protegerles de juicios sectáreos: «La libre facultad de sospecha — asegura solemnemente PAGANO— es el asilo sagrado contra las opresiones, y el más fuerte amparo de la libertad civil» ${ }^{115}$.

En la configuración del modelo de juez, el discurso paganiano añade un elemento más al del carácter de tercero del juez y al de su corolario de la recusabilidad: el de la colegialidad. Las preferencias de PAGANO se dirigen sin duda al jurado popular ${ }^{116}$, inspirado en una orientación muy difundida en la teoría penal ilustrada. También MoNTESQUIEU, seguido fielmente por BECCARIA ${ }^{117}$, se había pronunciado en contra de un «senado permanente» y a favor de un juicio deliberado por jurados «de la misma condición del acusado» ${ }^{118}$. También FILANGIERI, animado por la experiencia inglesa, había exaltado el modelo del juez-ciudadano, y denigrado al mismo tiempo, con palabras cargadas de desprecio y desaprobación, la magistratura profesional de los tribunales, «dependientes mercenarios del jefe de la nación» ${ }^{119}$.

PAGANO no recoge la idea montesquieuana de la imparcialidad de los pares, ni las sugerencias polémicas filangierianas contra los jueces de toga; él funda su posición sobre un argumento diferente que, en efecto, no se dirige específicamente a favor del jurado popular, sino más en general, a favor del tribunal colegiado: «Quienes sobre la vida y la libertad de los ciudadanos deben juzgar —escribe-, conviene que sean lo más

\footnotetext{
107 Ibidem, p. 93.

${ }^{108}$ Ibidem, cap. XXIV, p. 119.

109 Montesquieu, 1748: lib. XI, cap. VI, p. 311.

110 BeCCARIA, 1774: XIV, p. 35.

${ }^{111}$ Cfr. FilangIERI, 2003: lib. III, parte I, cap. XVI, pp. 148-164.

112 Cfr. CSP, cap. XXIV, pp. 120-125.

${ }_{113}$ Cfr. Ibidem, cap. XXV, pp. 126-127, y FILANGIERI, 2003: lib. III, parte I, cap. XVI, p. 160.

${ }^{114}$ Cfr. FilangIERI, 2003: lib. III, parte I, cap. XVI, p. 160.

115 CSP, cap. XXIV, p. 119.

116 Cfr. ibidem, cap. XXIV, pp. 118-125; cap. XXVI, pp. 130-133.

117 BECCARIA, 1774: XIV, p. 35.

118 Montesquieu, 1748: lib. XI, cap. VI, pp. 311-312.

119 FilangIERI, 2003: lib. III, parte I, cap. XVI, p. 162.
} 
numerosos que se pueda» porque, de ese modo, «el asunto será examinado en todos sus aspectos, y cada uno tomará en consideración algo que haya pasado inadvertido a los otros; de forma que, al ser más numerosos los datos sobre los que recaerá el juicio, este será más veraz y más exacto» ${ }^{120}$. El tribunal colegiado, por tanto, es considerado como un factor importante de garantía en la medida en que disminuye el riesgo de error judicial. Existe, además, otra razón que lo hace preferible al juzgado unipersonal: «no hay cosa que frene más el arbitrio de un juez que el colegio de muchos jueces» ${ }^{121}$.

Se trata evidentemente de una razón de importancia crucial en la lógica del pensamiento procesalista de PAGANO. Su garantismo penal es, de hecho, una doctrina acerca de la limitación de la discrecionalidad potestativa del juez. Limitación que, si en la colegialidad del órgano juzgador encuentra una importante garantía, halla su principal instrumento de efectividad en los vínculos normativos que dirigen la actividad judicial.

El ideal del gobierno de la ley, piedra angular del republicanismo de PAGANO ${ }^{122}$, se implanta con fuerza en el ámbito del proceso. A la «autoridad» del «soberano filósofo [...] de PLATÓN» ${ }^{123}$, que deseaba dejar el curso de los juicios en manos de la sabiduría de los magistrados ${ }^{124}$, las Consideraciones oponen la concepción ilustrada del juez «órgano de la ley» ${ }^{125}$. Parafraseando la célebre fórmula de MONTESQUIEU ${ }^{126}$, PAGANO apoya un sistema penal donde el juez sea «el simple brazo y la voz de la ley; más aún, es la ley misma, animada y con voz, y nada más» ${ }^{127}$. Sólo así él ve satisfecha la exigencia de certeza jurídica, entendida como prerrequisito de la libertad del ciudadano: «se puede establecer el principio constante de que cuanto más grande sea el arbitrio del juez menos asegurada está la libertad civil [...]. Feliz y afortunado [aquel pueblo] donde infinito sea el poder de las leyes y muy limitado el del juez» ${ }^{128}$.

PAGANO da por ello una particular importancia a la formalización legal del procedimiento. La ley debe fijar «la serie, el orden de acciones judiciales, y el método, de acuerdo con el cual el juez se debe conducir en la investigación del delito y del reo» ${ }^{129}$; en otras palabras, la ley debe prescribir «el orden y el método para obtener» las prue-

120 CSP, cap. XXIV, p. 119.

121 Ibidem.

${ }^{122}$ Cfr. IPPOLITO, 2004: «Per una lettura in chiave politica dei Saggi politici: F. M. PAgANO e la teoria delle forme di governo», en L'Acropoli, V, 3: pp. 320-333, y id., 2006: «Repubblica e monarchia nel pensiero politico di Francesco Mario Pagano», en Il Pensiero politico, XL, 3: pp. 369-400.

${ }_{123}$ CSP, cap. III, p. 14.

${ }^{124}$ Cfr. Platón, 1970: Le Leggi, lib. IX, 876c, en Dialoghi politici, ed. de F. AdORnO, Turín: Utet, p. 391 : en la medida «en que los tribunales se hallen establecidos con toda la rectitud posible y los futuros jueces estén bien formados y probados con todo rigor, será recto, bueno y decoroso el encomendar a tales jueces lo más de los juicios acerca de los culpables y de lo que deben sufrir y pagar». [PLATÓN, 1999: Las leyes, Madrid: CEPC, edición bilingüe, traducción, notas y estudio preliminar de J. R. PABÓN y M. FERnÁNDEZ-GALIANO, por la que se cita en esta traducción ( N. de la T.)].

125 La expresión está en FILANGIERI, 2003: lib. III, parte I, cap. XX, p. 180.

126 «Los jueces de la nación como es sabido, no son más ni menos que la boca que pronuncia las palabras de la ley, seres inanimados que no pueden mitigar la fuerza y el rigor de la ley misma», en MONTESQUIEU, 1748: lib. XI, cap. VI, p. 317 [MonTESQUIEU, 1989: El espíritu de las leyes, trad. castellana por la que se cita, N. Es-

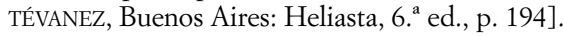

${ }^{127}$ CSP, cap. V, p. 21.

128 Ibidem.

129 CSP, cap. III, p. 12. 
bas, «para proporcionar la defensa al reo, y para dictar todas las resoluciones necesarias hasta la sentencia final» ${ }^{130}$. Apoyándose en la autoridad de BLACKSTONE, PAGANO defiende, frente a su extendido descrédito, las formalidades procesales, consideradas por la opinión vulgar como impedimentos inútiles al rápido curso de la justicia. Él subraya por contra su valor garantista: son «las trincheras y los baluartes de la libertad civil» ${ }^{131}$. Frente al sistema contemporáneo donde «las manos del inquisidor están libres de ataduras y la libertad civil no está asegurada» ${ }^{132}$, contrapone un modelo judicial en el cual «el freno de la reglamentación del proceso [...] detenga el arbitrio ilimitado del juez» ${ }^{133}$.

La crítica que PAGANO dirige contra el procedimiento inquisitivo entonces vigente no se articula sólo en el nivel del déficit de garantías del imputado, tradicional argumento crítico de los partidarios del modelo acusatorio; este autor desafía a sus adversarios, o sea, a los apologetas de la inquisitio, en su propio terreno: el de la exigencia represiva. Su concepción del proceso penal como defensa de la libertad individual lo era tanto contra los propios delitos como contra los castigos injustos, y ello le lleva a prestar tanta atención a la necesidad de asegurar que los delincuentes sean llevados ante la justicia como a proteger a los inocentes.

De esta forma, en el examen de las «opiniones erróneas y de los graves desórdenes [...] de los juicios penales» ${ }^{134}$, no deja de subrayar la escasa eficacia represiva del procedimiento practicado por los tribunales napolitanos, al que califica de «un monstruo [...] nacido de la unión del proceso inquisitivo y del proceso acusatorio» ${ }^{135}$, donde la función de garantía de los elementos de este último, adheridos al tronco de la inquisitio, viene completamente trastocada, y tales injertos no tienen otro efecto que el de abrir el paso a la impunidad.

También desde esta perspectiva PAGANO insiste sobre las consecuencias devastadoras de la amplitud de los poderes del juez, fuente no sólo de procedimientos y castigos arbitrarios, sino también de otras igualmente arbitrarias (pero ciertamente menos casuales) ${ }^{136}$ «absoluciones»: «la salvación del reo» está «en manos del inquisidor» tanto como lo está «la opresión del inocente» ${ }^{137}$. A juicio de PAGANO, un proceso fundado sobre el secreto, sobre la instrucción escrita, y desprovisto de debate es, al mismo tiempo, «fatal para la inocencia» y «favorable a la impunidad» ${ }^{138}$.

Éste es, sin duda, el motivo dominante en las Consideraciones: la denuncia del fracaso absoluto del método procesal entonces vigente, que arrojaba a los súbditos del reino de Nápoles a una condición de total inseguridad y precariedad, exponiéndolos a las ofensas de los delincuentes y a los abusos de los inquisidores. Más allá de esta denuncia, la reflexión de PAGANO desembocaba, como se ha tratado de demostrar, en una

${ }^{130}$ Ibidem, p. 13.

131 Ibidem.

132 Ibidem, cap. XX, p. 97.

133 Ibidem, cap. III, p. 13-14.

134 CSP, cap. XXXII, p. 158.

135 Ibidem, cap. XV, p. 76.

136 «Los delitos de los ricos son cubiertos por el áureo manto de la fraterna caridad de los subalternos» (ibidem, cap. XVII, p. 81).

137 Ibidem, cap. XIX, p. 96.

138 Ibidem, p. 88. 
doctrina orgánica procesalista que, articulándose sobre los principios de la legalidad del proceso, de la imparcialidad del juez, de la paridad de poderes entre acusación y defensa, del contradictorio, de la oralidad y de la publicidad de todo el procedimiento, daba forma a un coherente sistema de garantías en el que encontraban expresión y orden las razones políticas y las principales instancias de la Ilustración penal.

(Traducción de Kira Ciófalo) 